\title{
Effects of lockdown on retinal detachment incidence in Scotland
}

\author{
Fatemeh Shams $\mathbb{D}^{1} \cdot$ Mariam El-Abiary $^{1} \cdot$ Colin Goudie $^{2} \cdot$ David Yorston $^{1}$
}

Received: 19 May 2020 / Revised: 5 June 2020 / Accepted: 8 June 2020 / Published online: 17 June 2020

(c) The Royal College of Ophthalmologists 2020

\section{To the Editor:}

Wickham et al. [1] have highlighted the impact of COVID policies on ophthalmology services. Their findings are supported by our experience in Scotland. Rhegmatogenous retinal detachments (RRDs) are acute conditions that require prompt surgery [2]. The annual incidence of RRDs in Scotland was reported as 12.05/100,000 in 2010 [3].

The SARS-CoV-19 outbreak has been unprecedented. Healthcare services have worked hard to stay afloat. Subspecialty care has taken a back seat to intensive care and acute COVID wards. With UK eye departments providing only emergency care, outpatient clinics have been cancelled and workloads reduced. Anecdotal evidence from units all over the country suggests that RRD presentations have declined.

Fortuitously, since August 2019 a study has been running across Scotland, prospectively collating all new RRDs, aiming to establish the incidence 10 years after the Scottish Retinal Detachment Study [3]. This has allowed us to assess the impact of the COVID-19 lockdown on RRD presentations.

Fifteen surgeons in all six Vitreoretinal units across Scotland prospectively recorded all RRD presentations since August 2019. These records were collated centrally. Details such as age, sex, laterality and macular status were documented. We examined the data prior to and 5 weeks after the UK lockdown on the $23^{\text {rd }}$ March 2020. As the announcement was late in the afternoon, most of the RRDs operated on the $24^{\text {th }}$ would have presented prior to this. We therefore started counting the post lockdown numbers from $25^{\text {th }}$ March.

Fatemeh Shams

fshams@doctors.org.uk

1 Tennet Institute of Ophthalmology, Gartnavel General Hospital, Glasgow, UK

2 Princess Alexandra Eye Pavilion, Edinburgh, UK
We averaged the total number of RRDs in four 5-week periods (excluding Christmas and New Year) leading up to $25^{\text {th }}$ March and compared this to the 5 weeks from $25^{\text {th }}$ March to $29^{\text {th }}$ April (Table 1). The weekly mean RRDs reduced from 18.2 before lockdown, to 8.6 after lockdown, resulting in a drop in the annual incidence from 17.37/ 100,000/year to 8.21 (CI 7.8-10.5, $p<0.0001$ ). There has also been a decrease in the proportion of RRDs that are macula on at presentation from $44.2 \%$ to $34.9 \%$ (Table 1).

Extrapolating this data to the UK population, we estimate that the weekly number of detachments has declined from 222 to 105 , suggesting that 117 RRDs are going untreated for every week of lockdown.

There has been a substantial reduction in the number of people presenting with retinal detachment in Scotland, following the lockdown. This may be due to a fear of attending hospital owing to the perceived risk of coronavirus infection, the lack of an accessible referral route with closure of high street optometrists, or a misunderstanding of the "Stay at Home" advice. It is very unlikely that the incidence of retinal detachment has declined (Table 2).

Although the reduction reported by Wickham et al. [1] was not as steep, we agree with them that we should plan for a surge in untreated and complex conditions as the lockdown is eased.

As prompt treatment is essential for a good outcome, when these patients do attend, the delay will lead to significantly worse functional outcomes. This represents another example of the hidden harms of the COVID-19 pandemic. 
Table 1 Table showing the weekly average of RRD presentations from four 5-week periods pre lockdown compared to the numbers in the 5 weeks post lockdown.
Total number of RRDs Weekly average Percentage of macula on cases

\begin{tabular}{lrrl}
\hline Weeks $19^{\text {th }}$ Aug to $22^{\text {nd }}$ Sept & 98 & 19.6 & $40.8 \%$ \\
Weeks $30^{\text {th }}$ Sept to $3^{\text {rd }}$ Nov & 102 & 20.4 & $42.2 \%$ \\
Weeks $18^{\text {th }}$ Nov to $22^{\text {nd }}$ Dec & 78 & 15.6 & $53.8 \%$ \\
Weeks $17^{\text {th }}$ Feb to $22^{\text {nd }}$ Mar & 86 & 17.2 & $41.9 \%$ \\
Weeks $25^{\text {th }}$ Mar to $29^{\text {th }}$ Apr & 43 & 8.6 & $34.9 \%$ \\
\hline
\end{tabular}

Table 2 The difference in the number of weekly RRD presentations in Scotland before and after lockdown was commenced.

$\begin{array}{ll}5 \text { weeks average pre } & 5 \text { weeks post } \\ \text { lockdown } & \text { lockdown }\end{array}$

Scotland

Mean weekly RRDs

18.2

Annual Incidence

17.37

$(/ 100,000)$

Extrapolated to UK population

Estimated weekly RRDs 222.04

104.92

Scottish population estimate $5,463,300$ and UK population estimate 66,435,600 (Source: UK Office for National Statistics [4]).

\section{Compliance with ethical standards}

Conflict of interest The authors declare that they have no conflict of interest.
Publisher's note Springer Nature remains neutral with regard to jurisdictional claims in published maps and institutional affiliations.

\section{References}

1. Wickham L, Hay G, Hamilton R, Wooding J, Tossounis H, de Cruz $\mathrm{L}$, et al. The impact of COVID policies on acute ophthalmology services-experiences from Moorfields Eye Hospital NHS Foundation Trust. Eye. 2020. https://doi.org/10.1038/s41433-020-0957-2.

2. Grey RH, Burns-Cox CJ, Hughes A. Blind and partial sight registration in Avon. Br J Ophthalmol. 1989;73:88-94.

3. Mitry D, Charteris D, Yorston D, Siddiqui MAR, Campbell H, Murphy AL, et al. The epidemiology and socioeconomic associations of retinal detachment in Scotland: a two-year prospective population-based study by the Scottish RD Study Group. Investig Ophthal Vis Sci. 2010;5:4963-8.

4. UK Office for National Statistics-Population Estimates. https://www.ons.gov.uk/peoplepopulationandcommunity/popula tionandmigration/populationestimates. 